\title{
Acute Chest Syndrome in Children with Sickle Cell Disease
}

\author{
Shilpa Jain, MD,MPH, Nitya Bakshi, MBBS, MS,2 and Lakshmanan Krishnamurti, MD²
}

Acute chest syndrome (ACS) is a frequent cause of acute lung disease in children with sickle cell disease (SCD). Patients may present with ACS or may develop this complication during the course of a hospitalization for acute vaso-occlusive crises (VOC). ACS is associated with prolonged hospitalization, increased risk of respiratory failure, and the potential for developing chronic lung disease. ACS in SCD is defined as the presence of fever and/or new respiratory symptoms accompanied by the presence of a new pulmonary infiltrate on chest X-ray. The spectrum of clinical manifestations can range from mild respiratory illness to acute respiratory distress syndrome. The presence of severe hypoxemia is a useful predictor of severity and outcome. The etiology of ACS is often multifactorial. One of the proposed mechanisms involves increased adhesion of sickle red cells to pulmonary microvasculature in the presence of hypoxia. Other commonly associated etiologies include infection, pulmonary fat embolism, and infarction. Infection is a common cause in children, whereas adults usually present with pain crises. Several risk factors have been identified in children to be associated with increased incidence of ACS. These include younger age, severe SCD genotypes ( $\mathrm{SS}$ or $\mathrm{S} \beta^{0}$ thalassemia), lower fetal hemoglobin concentrations, higher steady-state hemoglobin levels, higher steady-state white blood cell counts, history of asthma, and tobacco smoke exposure. Opiate overdose and resulting hypoventilation can also trigger ACS. Prompt diagnosis and management with intravenous fluids, analgesics, aggressive incentive spirometry, supplemental oxygen or respiratory support, antibiotics, and transfusion therapy, are key to the prevention of clinical deterioration. Bronchodilators should be considered if there is history of asthma or in the presence of acute bronchospasm. Treatment with hydroxyurea should be considered for prevention of recurrent episodes. This review evaluates the etiology, pathophysiology, risk factors, clinical presentation of ACS, and preventive and treatment strategies for effective management of ACS.

Keywords: acute chest syndrome, sickle cell disease, children, pulmonary

\section{Introduction}

A CUTE CHEST SYNDROME (ACS) is a frequent complication of sickle cell disease (SCD) in patients hospitalized with vaso-occlusive crisis (VOC). It is associated with a high risk of sickle cell-related mortality and morbidity in children, including prolonged hospitalization. More than half of all children with homozygous SCD (HbSS) experience at least one episode of ACS in the first decade of life. ${ }^{1}$ Recurrent episodes may herald the onset of debilitating chronic lung disease. $^{2}$ Although most of the evidence for clinical management and prevention is derived from the experience in patients with $\mathrm{HbSS}$, ACS should be aggressively managed irrespective of the SCD genotype. This article reviews the etiology, pathophysiology, risk factors, clinical features, diagnosis, treat- ment, and preventive strategies of ACS in pediatric patients with SCD.

\section{Etiology and Pathophysiology}

ACS is a form of acute lung injury in SCD. The development of ACS represents a vicious cycle of lung infarction, inflammation, and atelectasis leading to ventilation-perfusion mismatch, hypoxemia, and acute increases in pulmonary artery and right ventricular pressures. ${ }^{3}$ At the cellular level, in the presence of low alveolar oxygen tension, abnormal rheology of the sickled red blood cells (sRBCs) facilitates adhesion to each other, leukocytes, and the vascular endothelium, resulting in vaso-occlusion and tissue hypoxia. These interactions also cause the release of inflammatory cytokines which promote

\footnotetext{
${ }^{1}$ Department of Pediatrics, Division of Pediatric Hematology-Oncology, Women and Children's Hospital of Buffalo, Hemophilia Center of Western New York, Buffalo, New York.

${ }^{2}$ Department of Pediatrics, Division of Pediatric Hematology-Oncology, Aflac Cancer and Blood Disorders Center, Children's Healthcare of Atlanta, Atlanta, Georgia.

(C) Shilpa Jain et al. 2017; Published by Mary Ann Liebert, Inc. This is an Open Access article distributed under the terms of the Creative Commons Attribution License, which permits unrestricted use, distribution, and reproduction in any medium, provided the original work is properly cited.
} 
acute and chronic inflammation in the airways by virtue of being in close proximity with the vasculature. ${ }^{4}$ Evidence for this pathophysiological mechanism comes from markedly elevated plasma levels of vascular cell adhesion molecule-1, an adhesion receptor on endothelial cells, in patients with ACS along with significantly lower levels of cytoprotective factors such as nitric oxide (NO) metabolites. ${ }^{5}$ The three major identifiable etiologies for the development of ACS are pulmonary infections, pulmonary fat embolism from necrotic bone marrow, and pulmonary infarction as outlined in Fig. 1. ${ }^{6}$

\section{Pulmonary infection}

The multicenter National Acute Chest Syndrome Study (NACSS) evaluated 671 ACS episodes in 538 patients and nearly half of the patients were children and adolescents. ${ }^{6} \mathrm{~A}$ specific cause for ACS was found in only $38 \%$ of episodes with infection as a leading etiology in children. The infectious organisms which were identified in the study included Chlamydia pneumoniae, Mycoplasma pneumoniae, respiratory syncytial virus (RSV), Staphylococcus aureus, Streptococcus pneumoniae, and other pathogens in decreasing order of frequency. Viral infections were more common in children $<10$ years of age. Infections can precipitate an ACS episode in a susceptible SCD patient by inducing an excessive inflammatory lung injury response in the presence of a damaged lung microvasculature. ${ }^{5-8}$ This has been further demonstrated in transgenic mouse models of HbSS, which develop lung injury at low endotoxin levels that do not adversely affect the wild-type mice. ${ }^{9,10}$ The incidence of $S$. pneumoniae infection in the recent years has decreased as more effective vaccines are available and widely used. Influenza, notably the H1N1 strain, also produces seasonal outbreaks of ACS and may cause severe disease. ${ }^{11}$ Parvo- virus B19 through its association with bone marrow infarction/necrosis and potentially pulmonary fat embolism can also result in ACS. ${ }^{12}$

\section{Pulmonary fat embolism}

Pulmonary fat embolism, with or without pulmonary infection, can cause ACS in both adults and children. ${ }^{6}$ During acute pain episodes, infarcted and necrosed bone marrow (especially of the pelvis and femur) release fat droplets in the bloodstream, which embolize to the lungs. Fat emboli in the lung vasculature are metabolized to free fatty acids, including secretory phospholipase A2 (sPLA2), which mediate alveolar inflammation and endothelial injury. ${ }^{13}$ Diagnosis of pulmonary fat embolism in NACSS was based on quantitative evaluation of oil red-positive fat-laden alveolar macrophages in bronchoalveolar lavage (BAL) or induced sputum specimens. Although this method is sensitive for the diagnosis of pulmonary fat embolism, its specificity and clinical usefulness is questionable since fat-laden alveolar macrophages are also associated with microaspiration, gastroesophageal refluxrelated respiratory disease, and hyperlipidemia. ${ }^{14-16}$ The presence of these additional factors can influence the detection of the fat-laden macrophages.

\section{Pulmonary infarction and in situ thrombosis}

Pulmonary infarction is another major contributor to the development of ACS and was determined to be the cause in $16 \%$ of ACS episodes in NACSS. This occurs as a result of increased adhesion of sRBCs to the endothelium causing vaso-occlusion, which leads to ventilation-perfusion mismatch and exacerbation of hypoxemia. ${ }^{17}$ In a small subset of patients, computed tomography (CT)-pulmonary angiography identified subsegmental thromboembolism in $17 \%$ of
FIG. 1. A vicious cycle in the pathogenesis of ACS, involving RBC sickling, cellular adhesion, hemolysis, and vasoocclusion. Common causes for the development of ACS include fat embolism, pulmonary infection, pulmonary infraction, and hypoventilation. Reprinted from Chest, 149 (4), Enrico M. Novelli and Mark T. Gladwin, Crises in Sickle Cell Disease, 10821093, Copyright (2016), with permission from Elsevier. ACS, acute chest syndrome; PLT, platelet; RBC, red blood cell; WBC, white blood cell. Color images available online at www.liebertpub.com/ped

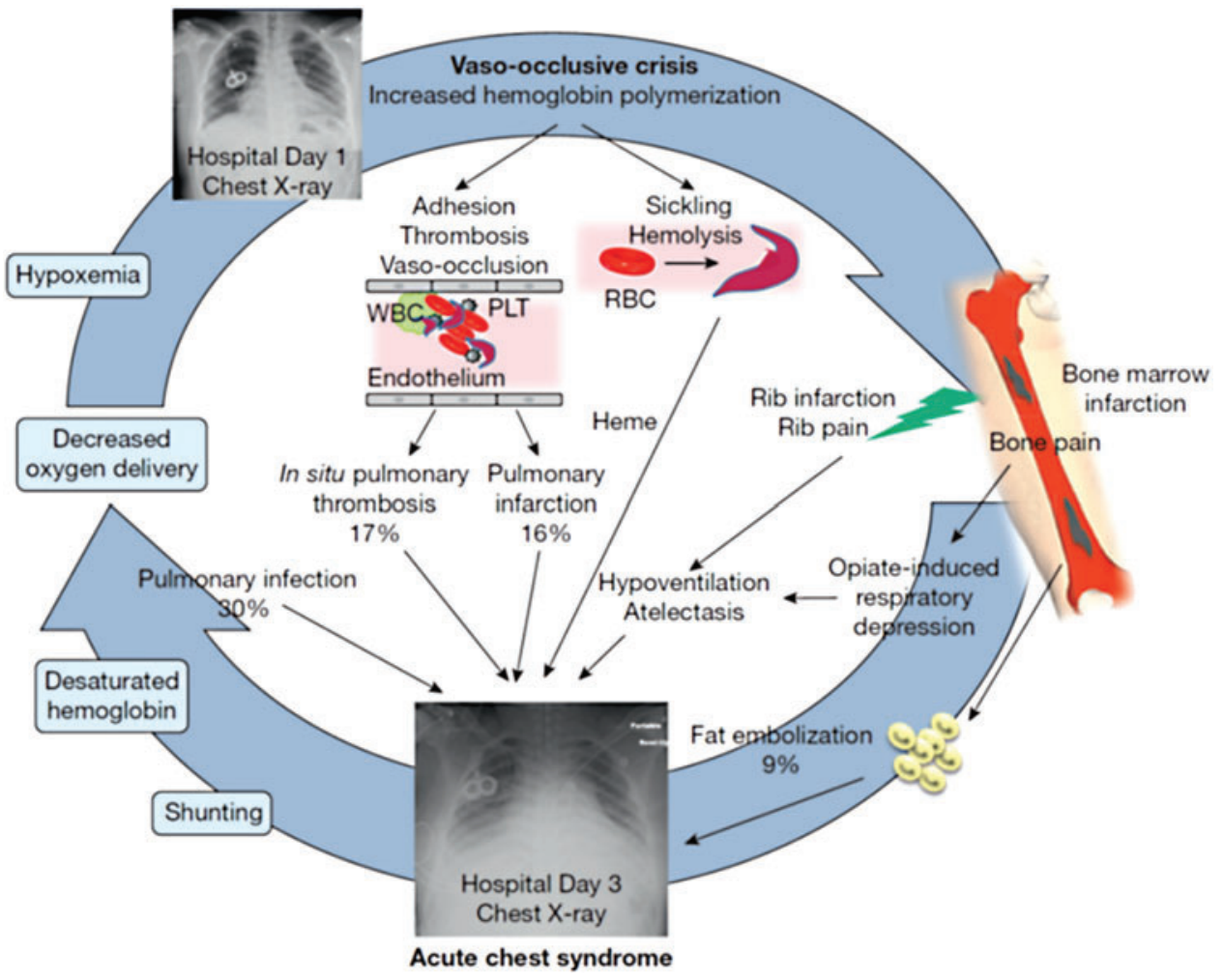


ACS episodes without associated peripheral thrombosis, possibly suggestive of in situ thrombosis leading to infarction. ${ }^{18}$ Furthermore, there is a high prevalence of pulmonary embolism in patients with SCD associated with thrombosis in the distal venous circulation. ${ }^{19,20}$ This underappreciated entity may contribute to the pulmonary symptoms associated with ACS and also increase the risk of mortality. ${ }^{6,21}$

\section{Hypoventilation}

Splinting caused by rib infarction can lead to decreased respiratory effort resulting in hypoventilation and atelectasis. $^{22}$ This may be further exacerbated by excessive opioid administration or following general anesthesia. ${ }^{6,23}$ As a result, pooling of secretions at lung bases occurs and predisposes to ventilation-perfusion mismatch and tissue hypoxia.

\section{Biomarkers of ACS}

Some investigators have sought to define objective biomarkers to predict the occurrence of ACS based on the understanding of the pathophysiology. Serum concentration of sPLA2 was shown to be elevated in a small group of patients with ACS and also correlated with clinical severity. ${ }^{13}$ In a follow-up study, elevation was detected even $24-48 \mathrm{~h}$ before clinical onset of ACS in children during hospitalization for VOC. $^{24}$ These findings have been variably replicated with elevated levels found in $80 \%$ of subjects with ACS participating in a multicenter trial, ${ }^{25}$ but with a poor positive predictive value of $24 \%$ in another cohort of patients hospitalized for acute pain episodes. ${ }^{26}$ Moreover, the time it takes to perform the test makes it impractical for clinical use as enzyme-linked immunosorbent assay-based assays are not widely available in clinical laboratories. $^{24}$

C-reactive protein, an acute-phase reactant, was suggested as a surrogate for sPLA2 and was found to have serum concentrations that paralleled those of sPLA2 during the hospital course of 20 patients with SCD admitted for VOC and $\mathrm{ACS}{ }^{27}$ Whether CRP can be used as a substitute for predicting development of ACS in patients with VOC is not clear. Another acute-phase reactant, pentraxin-related protein (PTX3), has been found to be elevated in SCD patients with VOC, similar to the levels seen in other inflammatory and ischemic states. ${ }^{28}$ Patients with higher initial PTX3 concentrations have been found to be more likely to develop ACS and were observed to have further increase in PTX3 levels upon progression to ACS. ${ }^{29}$ But there is a lack of feasibility in using these biomarkers in the clinical setting to predict occurrence of ACS as these tests are not widely available.

\section{Clinical Presentation}

A classical episode of ACS is defined as an acute illness characterized by the finding of a new segmental pulmonary infiltrate consistent with consolidation, but not atelectasis along with one or more new respiratory symptoms or signs, such as cough, chest pain, fever $\left(>38.5^{\circ} \mathrm{C}\right)$, hypoxemia, and tachypnea. ${ }^{8,30}$ Various other definitions of ACS have been used in clinical practice and research, but none considers rate of decline of respiratory status as a diagnostic criteria and thus lack specificity. ${ }^{31}$ ACS is often a clinical diagnosis especially in the presence of hypoxemia as radiographic changes may lag behind clinical findings. It can mimic bacterial pneumonia, asthma exacerbation, or bronchiolitis at presen- tation. It can also progress rapidly from mild hypoxemia to acute respiratory failure within $24 \mathrm{~h}$ of onset of respiratory symptoms, which in itself constitutes a distinct clinical phenotype of ACS. ${ }^{6,30,32}$ This form of rapidly progressive ACS is seen more commonly in adults as compared with children with SCD, and is frequently associated with thrombocytopenia and multiorgan failure. ${ }^{32-34}$ The etiology and underlying pathophysiological mechanisms of this subgroup of ACS are unclear, but shares resemblance with other thrombotic microangiopathic syndromes. ${ }^{32,34,35}$

The presentation, causal mechanisms, and natural course of ACS differ considerably with age. The highest incidence of ACS is in children $<10$ years of age ${ }^{36}$ with frequently occurring triggers in the form of pulmonary infections. ${ }^{6}$ As a result, they usually present with fever, cough, and wheeze. Older children and adults more frequently present with dyspnea and chest pain and tend to follow a more severe course. ${ }^{6,30}$ Adults also tend to present with lower mean oxygen saturations because of a higher prevalence of pulmonary fat embolism. ${ }^{6}$ Children usually present with isolated upper or middle lobe involvement as compared with bilateral lower or multiple lobes in adults. ${ }^{6}$

A close temporal relationship exists between ACS and VOC. Nearly half of all ACS episodes occur between 1 and 3 days after admission for severe VOC, ${ }^{6}$ suggesting that VOC may be a prodromal event for the development of ACS. A retrospective report from a single institution revealed that approximately a third of patients who developed ACS had sought acute care for painful VOCs (mostly chest and back) within 2 weeks of hospitalization for ACS. ${ }^{37}$ Buchanan et al. ${ }^{38}$ have suggested that opioid selection for the treatment of VOC episodes may have an impact on the development of ACS, with patients receiving Nubain (Nalbuphine) less likely to develop ACS; however, their results were confounded by the use of continuous infusion analgesia. This observation has not been studied in a prospective clinical trial.

Neurological complications, such as infarctive stroke, silent cerebral infarcts, and posterior reversible leukoencephalopathy syndrome, have been shown to be higher after severe episodes of ACS in children. ${ }^{39-41}$ These neurological events have also been seen with platelet counts $<200,000$ per cumm in children hospitalized with ACS. ${ }^{6}$

\section{Risk Factors}

Several prospective and retrospective studies have attempted to identify risk factors for the prediction of development, recurrence, and severity of ACS. Based on these data, Table 1 lists risk factors that have been found to be associated with the development of ACS episodes.

In the prospective multicenter Cooperative Study of Sickle Cell Disease (CSSCD), younger age, lower fetal hemoglobin $(\mathrm{HbF})$ concentration, higher steady-state $\mathrm{Hb}$, and higher steady-state white blood cell (WBC) counts were found to be significant risk factors for ACS. ${ }^{36}$ Those with more severe genotypes (HbSS and $\operatorname{HbS} \beta^{0}$ thalassemia) had a greater risk of developing ACS than the milder ones (HbSC and $\mathrm{HbS}^{+}$thalassemia). ${ }^{36}$ In a retrospective study on 175 pediatric patients hospitalized for VOC, a significantly higher WBC $(19.1 \pm 4.8 / \mathrm{cmm}$ versus $13.2 \pm 5.2 / \mathrm{cmm})$ and lower admitting $\mathrm{Hb}$ level from baseline $(7.7 \pm 1.2 \mathrm{~g} / \mathrm{dL}$ versus $9.3 \pm 2.0 \mathrm{~g} / \mathrm{dL}$ ) were found in those who developed ACS. $^{38}$ These data suggest that a higher steady-state $\mathrm{Hb}$ 
Table 1. Clinical and Laboratory Predictors of Development of Acute Chest Syndrome

\begin{tabular}{lc}
\hline Risk factor & References \\
\hline Young age & 36 \\
Low HbF & 36 \\
High steady-state Hb & 36 \\
High steady-state WBC & $36,38,45$ \\
Severe genotypes & 36 \\
$\quad$ (HbSS and HbS $\beta^{0}$ thalassemia) & \\
$>3$ severe VOC episodes & 45 \\
$\quad$ in the preceding year & $45,62,65,69-75$ \\
Asthma/airway hyperreactivity & $57-60$ \\
Tobacco smoke exposure & 56 \\
Recent surgery & \\
\hline
\end{tabular}

$\mathrm{Hb}$, hemoglobin; HbF, fetal hemoglobin; HbS, sickle hemoglobin; HbSS, homozygous SCD; VOC, vaso-occlusive crises; WBC, white blood cell.

level likely promotes VOC by increasing blood viscosity, and acute hemolysis following VOC may contribute to the development of lung injury.

Higher levels of free heme (nonprotein bound) in plasma, a byproduct of hemolysis, were associated with increased odds of developing ACS [odds ratio $(\mathrm{OR})=2.56, P=0.016$ ] in a cohort of children with SCD. ${ }^{42}$ This observation is supported by the recent findings of a polymorphism in the promoter region of the heme oxygenase- 1 gene, involved in catabolism of heme, to be associated with degree of hemolysis and severity of ACS. ${ }^{43}$ A recent study in sickle cell mouse model suggests that extracellular hemin (the oxidized prosthetic moiety of $\mathrm{Hb}$ ) may contribute to ACS pathogenesis through toll-like receptor and provides a proof of principle for using recombinant hemopexin (a scavenger protein of free heme) as a therapeutic strategy for ACS in mice. ${ }^{44}$

In a large cross-sectional study, Pulmonary Hypertension and the Hypoxic Response in SCD, involving pediatric patients with HbSS and other sickle cell genotypes $(N=503)$, acute pulmonary events (either ACS or pneumonia) were found to be independently associated with $>3$ severe pain episodes in the preceding year irrespective of the genotype. ${ }^{45}$ In patients with $\mathrm{HbSS}$, significant associations for development of acute pulmonary events were also found with history of asthma, higher steady-state tricuspid regurgitant velocity (TRV), and higher WBC count. The prognostic significance of higher TRV in children is unclear as it has not been found to be particularly associated with ACS in other studies. ${ }^{46-48}$

Another risk factor that has been shown to predict recurrence of ACS episodes is a history of ACS in younger age, especially in the first 3 years of life, as reported by two independent cohorts of pediatric patients. ${ }^{49,50}$ Moreover, the highest incidence rate of recurrence has been reported to be within 6 months from the last event. ${ }^{51}$ Perhaps pulmonary injury from previous ACS episodes predisposes to increased susceptibility to recurrent events or alternatively a genetic predisposition underlies the development of frequent ACS episodes. ${ }^{52}$ A genetic association with ACS in patients with SCD, particularly in the younger age group, has been identified in the form of a single nucleotide involving $C O M M d 7$, which is a gene highly expressed in the lung that interacts with nuclear factor- $\mathrm{KB}$ signaling to control inflammatory responses. ${ }^{53}$

Certain risk factors are danger signals for a severe disease course, such as an arterial:alveolar oxygen gradient of $>30$ (on room air) as reported from a small series in children. ${ }^{54}$ Multilobar involvement, platelet count of $<200,000 /$ cumm at diagnosis, and history of cardiac disease were found to be independent predictors of respiratory failure in the NACSS study. ${ }^{6}$ A decrease in platelet count of more than $10 \%$ from steady state when admitted for VOC was also reported to be a significant predictor for developing ACS $(\mathrm{OR}=6.90)$ in a retrospective study of adult patients with SCD. ${ }^{55}$

General anesthesia, asthma/airway hyperreactivity, and smoking may act as triggers for the development of ACS in SCD. Patients undergoing an abdominal surgery, such as splenectomy and/or cholecystectomy, are especially at risk for developing ACS postoperatively secondary to hypoventilation/ atelectasis. ${ }^{56}$ Tobacco smoke exposure (TSE) either primary in adolescents and adults or secondary (at all ages) has been shown to be associated with increased rates of VOC and ACS. ${ }^{57-60}$ The mechanisms underlying the association between TSE and ACS, particularly in young children, could be related to impairment of lung growth/development in utero from secondhand TSE, increased viral respiratory illnesses, airway inflammation, and increased expression of adhesion markers. Secondhand smoke exposure can also cause pulmonary function abnormalities such as lower airway obstruction in children with SCD. ${ }^{61}$

\section{Asthma/airway hyperreactivity and ACS}

Asthma is common in children with SCD with occurrence estimates of $15 \%-28 \%^{62-64}$ and at least $55 \%$ have airway hyperreactivity without a clinical diagnosis of asthma. ${ }^{65-68}$ Asthma exacerbations in children with SCD have been associated with increased incidence of ACS episodes at a young age (median age of 2.4 years) ${ }^{62,65,69-75}$ Those with asthma are five times more likely $(\mathrm{OR}=4.9,95 \%$ confidence inter$\mathrm{val}=2.2-10.7)$ to present with respiratory symptoms at the time of a VOC. ${ }^{71}$ Several plausible explanations for the relationship between asthma and ACS or VOC are, ventilationperfusion mismatch, synergistic inflammatory response, and vascular leak. Although the importance of comorbid asthma in SCD outcomes is being increasingly recognized, there still remain substantial gaps in diagnosis and management.

\section{Management}

All patients with ACS should be hospitalized for careful monitoring of their oxygenation and clinical status. Patients benefit from early, aggressive intervention especially in the presence of risk factors such as multilobar involvement, coexisting respiratory diseases, and for whom blood is not readily available. Table 2 offers guidance for management based on an expert panel report from National Heart, Lung, and Blood Institute (NHLBI), ${ }^{76}$ which can be effectively put into clinical practice and lead to rapid resolution in majority of patients. As part of the initial workup, a child with SCD presenting with fever should have a CBC, reticulocyte count, blood culture, basic biochemistry, type and crossmatch, and a chest X-ray, irrespective of respiratory symptoms. A screening algorithm for ACS in pediatric patients with SCD is presented schematically in Fig. 2. Rapid screening tests in nasopharyngeal aspirates for RSV, influenza A (including H1N1 subtype), and influenza B, in season should be performed.

General principles of management in all patients with ACS are supportive care with hydration, antibiotics, pain control, and 
Table 2. General Guidelines for Management of Acute Chest Syndrome in Sickle Cell Disease

\section{A. Supportive care}

Goals

1. Adequate oxygenation

2. Prevention of atelectasis

\section{Hydration}

B. Transfusion therapy

1. Increase the $\mathrm{Hb}$ concentration to $9-11 \mathrm{~g} / \mathrm{dL}$ or reduce $\mathrm{HbS}$ levels to $<30 \%$

C. Medications

1. Pain control to prevent splinting and atelectasis

2. Respiratory infections

3. Presence of wheezing/ history of reactive airway disease
Maintain oxygen saturations $>94 \%$

Use noninvasive or mechanical ventilation if needed

Incentive spirometry

10 puffs q2 hours when awake

10 puffs q4 hours when sleeping

Patient mobilization

Chest physiotherapy

Maintain fluids $3 / 4 \quad 1 \times$ maintenance to avoid pulmonary edema

Avoid bolus IV fluids, unless hypotensive

Prompt institution of simple pRBC transfusion

Consider exchange transfusion with severe hypoxemia

$(\mathrm{PaO} 2<70 \mathrm{mmHg})$, multilobar disease, or rapidly

progressive disease

Analgesia (NSAIDs \pm Opioids)

Empiric coverage for pneumococcus and atypical organisms

(third-generation cephalosporin + Macrolide) \pm Vancomycin

if clinically unstable

Antivirals: Oseltamivir (Influenza season)

Bronchodilators

NSAID, nonsteroidal anti-inflammatory drug; pRBC, packed red blood cell.

maintenance of oxygenation and ventilation. Hydration is generally given with intravenously administered hypotonic fluids at approximately three-fourths of a maintenance rate as patients with ACS may be at risk for pulmonary edema. ${ }^{77}$

The use of aggressive incentive spirometry while awake to prevent atelectasis is an important aspect of management. ${ }^{78,79}$ Alternatively, the use of mechanical chest phys- iotherapy maneuvers, such as positive expiratory pressure devices, may be considered in younger children who may not be able to coordinate incentive spirometry or is limited by chest wall pain. ${ }^{80,81}$ The use of respiratory therapy warrants further study in patients with SCD at high risk for ACS. Supplemental oxygen should be given for oxygen saturation $\leq 94 \%$ and/or tachypnea. It is important to note

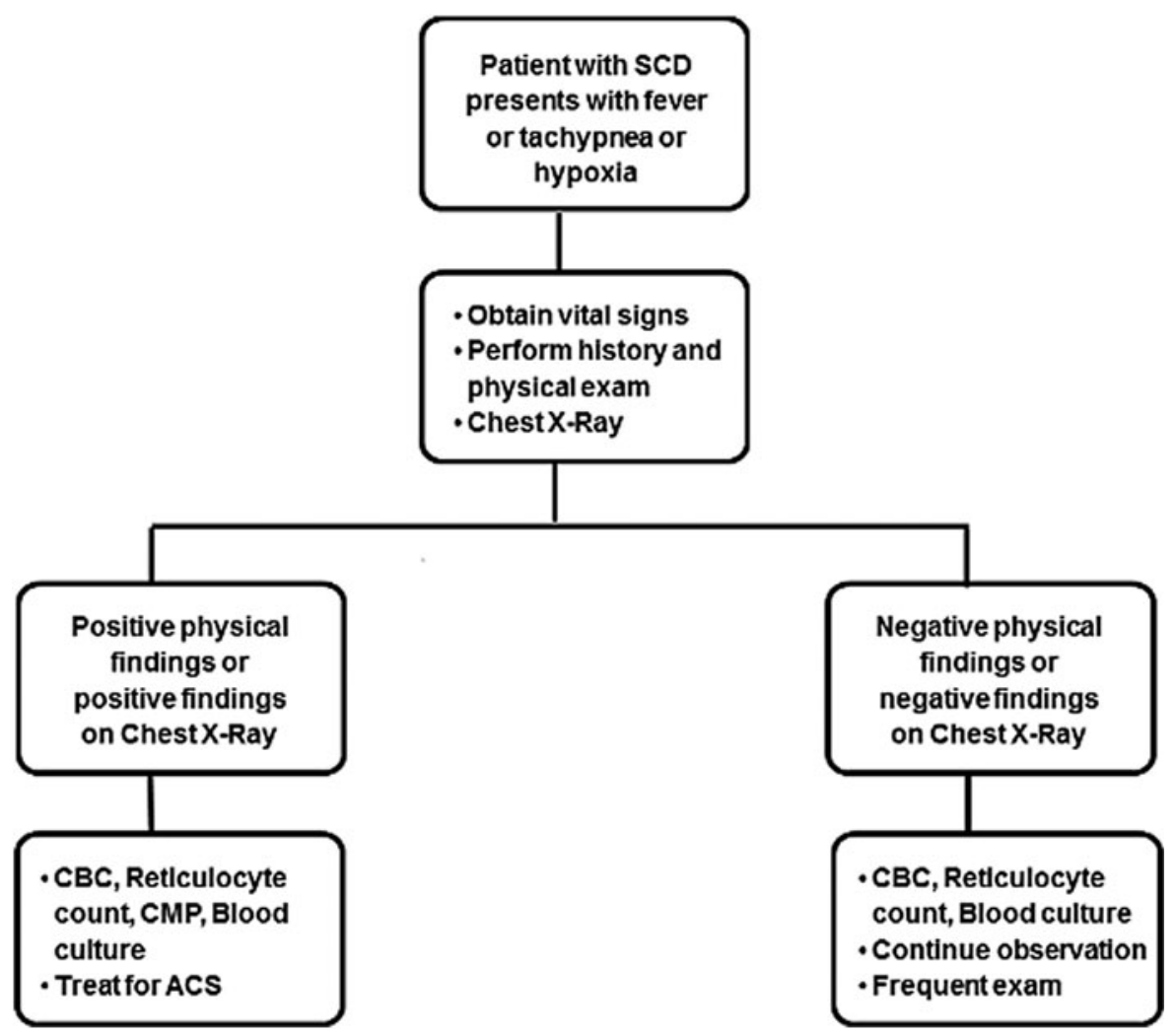

FIG. 2. Screening algorithm for ACS in pediatric patients with SCD. CBC, complete blood count, CMP, comprehensive metabolic panel; SCD, sickle cell disease. 
that patients might have chronic hypoxemia as a result of conditions such as pulmonary hypertension and chronic sickle lung disease, but any deterioration in oxygen saturation from baseline steady state warrants prompt action. Noninvasive ventilation such as bilevel positive airway pressure may be used to improve oxygenation and decrease work of breathing in patients with ACS. These benefits may prevent progression to respiratory failure and reduce the need for intubation and mechanical ventilation, but there is currently limited evidence regarding its precise role in managing children with $\mathrm{ACS}^{82}$ Indications for more intensive respiratory support include worsening hypoxemia, severe dyspnea, and respiratory acidosis $(\mathrm{pH}<7.35)$.

All patients with ACS should be started on empiric antibiotic coverage for pneumococcal infection, commonly with third-generation cephalosporins. Vancomycin should be added for coverage of Methicillin-resistant S. aureus infection in severely ill patients. Coverage for atypical bacteria with macrolide or another antibiotic is also indicated in the treatment for ACS, considering that these are the most common infectious agents and also contribute to severe disease. ${ }^{6,83,84}$ There are no clinical trials comparing the various antibiotic regimens. ${ }^{85}$ In the influenza season, empiric treatment with antiviral medication oseltamivir should be included, ideally started within $48 \mathrm{~h}$ of onset of symptoms.

Pain arising from thoracic bone infarction (ribs, sternum, and thoracic spine) leads to alveolar hypoventilation ${ }^{86}$ and is highly correlated with development of ACS. ${ }^{87}$ The goal of effective pain management should be to achieve a balance between analgesia to reduce respiratory splinting and hypoventilation, while avoiding respiratory depression. ${ }^{88}$ The presence of chest pain in adults with SCD, as compared with nonchest pain in $\mathrm{SCD}$, has been shown to be associated with the development of shallower breathing patterns along with reduced tidal volumes and resolution of the differences in tidal volumes after instituting opioid analgesia. ${ }^{89}$ Evidence from several randomized controlled trials (RCTs) and observational studies supports the use of around-the-clock administration of nonsteroidal antiinflammatory drugs (NSAIDs) and opioids to achieve adequate analgesia. ${ }^{90-95}$ Recommendations regarding types of analgesics and administration protocols may be referred to those developed by NHLBI based on expertise of the study panel and some were adapted from published guidelines from American Pain Society. ${ }^{76,96}$ NSAIDs solely can be used to treat mild-moderate pain with rapid addition of opioids if there is progression to severe pain. The NSAID, Ketorolac, is widely used, and is administered parenterally, but can only be used for 5 days. Morphine and Hydromorphone are commonly used as firstchoice opioid analgesics. Patients with ACS should be monitored for exacerbation of pain episodes and pain scores should be recorded along with vital signs to titrate analgesia. While not typical, the input of pain management specialists may be considered to guide pain management, particularly for patients who are sensitive to the sedative effects of opioids, or have chronic pain with tolerance to opioids.

Early and aggressive packed RBC (pRBC) transfusions, simple or exchange, (extended matching to D, C, E, and Kell antigens) result in improvements in oxygen saturation and Aa oxygen gradient. 6,97 Transfusions have considerably improved outcomes as demonstrated in the DeNOVO trial in which none of the 30 patients who received pRBCs required mechanical ventilation. ${ }^{98}$ Recommendation for transfusion in ACS from the NHLBI expert panel is to administer simple transfusion $(10 \mathrm{~mL} / \mathrm{kg} \mathrm{pRBCs})$ if $\mathrm{Hb}$ is more than $1 \mathrm{~g} / \mathrm{dL}$ below baseline, especially if baseline $\mathrm{Hb}$ is $<9 \mathrm{~g} / \mathrm{dL} .{ }^{76}$ The goal should be to either increase the $\mathrm{Hb}$ concentration to 9$11 \mathrm{~g} / \mathrm{dL}$ or reduce $\mathrm{Hb} \mathrm{S}$ levels to $<30 \%$. It has been noted in observational studies that simple transfusion is as effective as exchange transfusion in improving clinical outcomes and is adequate in most circumstances as front-line therapy for ACS. ${ }^{6,56}$ However, exchange transfusion should be considered in patients with severe or rapidly progressive illness requiring mechanical ventilation.

Children with SCD with history of ACS have worse pulmonary lung functions than age-matched children with SCD who have not experienced ACS. Various studies have reported a significant decrease in the percentage predicted FEV1 and FEV1/FVC ratio suggesting lower airway obstructive lung disease to be a common abnormality in children with ACS. ${ }^{67,99-101}$ Thus, for patients with airway hyperreactivity/asthma, use of bronchodilator therapy every $4 \mathrm{~h}$ is recommended irrespective of the presence of wheezing, even though its efficacy has not been tested in any RCTs. ${ }^{102}$ A short course of low-dose steroids has shown efficacy in attenuating the course of $\mathrm{ACS}^{103}$ and also decrease requirement for transfusion therapy. ${ }^{104}$ However, routine corticosteroid therapy for ACS is controversial in patients with SCD as its use has been associated with rebound pain crisis, hospitalization, ${ }^{103,105-108}$ and hemorrhagic stroke. ${ }^{109}$ It is noteworthy that risk of readmission for pain with steroids was reduced if patients had received transfusion therapy during the episode. $^{105}$

If a patient does not improve with supportive care and empiric antibiotics, consider diagnostic bronchoscopy with BAL to evaluate for other sources of infection and possible thoracocentesis if large effusions are present. In the presence of unexplained hypoxemia with absent clinical and X-ray findings, consider obtaining CT chest to evaluate pulmonary vasculature as well as lung parenchyma. In the presence of pulmonary embolism, treatment guidelines are the same as for the general population, although clinical research is ongoing to establish the role of anticoagulation for in situ thrombosis. The effectiveness of vasodilators such as inhaled NO has not been fully ascertained in clinical trials, but has shown some benefit in several case reports. ${ }^{110-112}$ Doppler echocardiogram should be performed in every patient admitted to the intensive care unit with ACS to diagnose right ventricular failure secondary to pulmonary hypertension which is associated with high mortality. ${ }^{113}$ Although this is more common in the adult population, but may present in late adolescence.

\section{Prevention}

ACS is the second most common cause for hospitalization after VOC in patients with SCD. Recurrent episodes of ACS in childhood may lead to sequelae such as obstructive and/or restrictive abnormalities, fibrosis, chronic hypoxemia, and early mortality. ${ }^{2,100}$ Thus, it is imperative to reduce the frequency of future episodes by implementing preventive interventions.

Prophylactic antibiotic administration with Penicillin VK, annual influenza (including H1N1) vaccination from 6 months of age, 23-valent pneumococcal polysaccharide vaccine ( $\geq 2$ years of age), 13-valent pneumococcal conjugate vaccine (shortly after birth), and avoidance of TSE may be beneficial in decreasing risk of developing ACS. All hospitalized patients with SCD should be carefully 
examined for respiratory symptoms and be continuously monitored by pulse oximetry to detect changes in oxygen saturation. The routine use of incentive spirometry at a prescribed regimen of 10 puffs every $2 \mathrm{~h}$ (while awake), in the setting of acute VOC and postsurgical state, has been shown to be effective in preventing ACS. ${ }^{79,114}$ Patients hospitalized for chest and back pain often require opioids to achieve analgesia to reduce respiratory splinting, doses of which should be optimally titrated to avoid causing oversedation and atelectasis. The secondary effects of hypoventilation and atelectasis resulting from opioids can be overcome by incentive spirometry. Preoperative blood transfusion is generally recommended in patients undergoing major surgery involving general anesthesia to prevent ACS postoperatively. ${ }^{115}$

Asthma, chronic obstructive pulmonary disease, restrictive lung disease, and obstructive sleep apnea are prevalent in 20\%$48 \%$ in SCD individuals. ${ }^{62,69,72}$ These respiratory disorders are associated with increased morbidity such as higher rates of ACS and decreasing lung function over time. ${ }^{62,72,73,116-118}$ There is also strong evidence for asthma and decreased FEV1 percent to be independent risk factors for mortality in SCD. ${ }^{11,119-121}$ Keeping this in mind, expert panel report from NHLBI recommends assessing for signs and symptoms of respiratory problems by history and physical in patients with SCD during routine clinic visits. If found to be symptomatic, objective assessment using pulmonary function tests should be done to determine the cause and institute appropriate treatment of the identified problem. ${ }^{76}$

A single episode of ACS at any age should prompt discussion with the family regarding therapy with hydroxyurea, a potent inducer of $\mathrm{HbF}$. It has been shown to be safe in both adults and children, including infants, and higher $\mathrm{HbF}$ levels have been inversely correlated with the development of ACS. ${ }^{122-126}$ In addition, hydroxyurea decreases the WBC count, which likely has a positive effect on decreasing endothelial inflammation and vaso-occlusion. ${ }^{127-131}$ Chronic transfusion therapy may also have a protective effect for ACS especially in those children with recurrent episodes of ACS, defined as two or more episodes within a 2-year period, and who do not respond or are not compliant with hydroxyurea. ${ }^{132}$ This effect has been demonstrated during the randomized Stroke Prevention Trial in which a dramatic reduction in ACS events was seen in the chronically transfused versus observation group (2.2 versus 15.7 events per 100 patient years, $P=0.0001){ }^{133}$ However, the use of chronic transfusions is also associated with additional morbidity of transfusional hemosiderosis, potential for alloimmunization, and includes risks of transmission of infections, and may not be an optimal long-term strategy. Lastly, stem cell transplant may be considered for recurrent ACS that is refractory to hydroxyurea while weighing in the risks versus benefits, donor availability, and patient age. ${ }^{134,135}$

\section{Conclusion}

ACS is a common complication of SCD necessitating frequent hospital admissions. Physicians caring for patients with SCD should be vigilant for the clinical features of early ACS so that optimal preventive and management strategies can be instituted. Families of affected patients should be educated about the seriousness of the complication and the need to seek immediate medical attention. Early and aggressive supportive care and transfusion therapy has been associated with a marked reduction in ACS-associated mortality. Hydroxyurea is a key preventive intervention. In the future, therapeutics using antiinflammatory, antipolymerization, and antiadhesive medications offer potential new approaches to the treatment of ACS.

\section{Author Disclosure Statement}

The authors have no relevant financial relationships to disclose.

\section{References}

1. Gill FM, et al. Clinical events in the first decade in a cohort of infants with sickle cell disease. Cooperative Study of Sickle Cell Disease. Blood 1995; 86:776-783.

2. Powars D, Weidman JA, Odom-Maryon T, Niland JC, Johnson C. Sickle cell chronic lung disease: prior morbidity and the risk of pulmonary failure. Medicine (Baltimore) 1988; 67:66-76.

3. Mekontso Dessap A, et al. Pulmonary hypertension and cor pulmonale during severe acute chest syndrome in sickle cell disease. Am J Respir Crit Care Med 2008; 177: 646-653.

4. Platt OS. Sickle cell anemia as an inflammatory disease. J Clin Invest 2000; 106:337-338.

5. Stuart MJ, Setty BN. Sickle cell acute chest syndrome: pathogenesis and rationale for treatment. Blood 1999; 94: 1555-1560.

6. Vichinsky EP, et al. Causes and outcomes of the acute chest syndrome in sickle cell disease. National Acute Chest Syndrome Study Group. N Engl J Med 2000; 342: 1855-1865.

7. Wun T. The role of inflammation and leukocytes in the pathogenesis of sickle cell disease. Hematology 2001; 5: 403-412.

8. Ballas SK, et al. Definitions of the phenotypic manifestations of sickle cell disease. Am J Hematol 2010; 85:613.

9. Holtzclaw JD, et al. Enhanced pulmonary and systemic response to endotoxin in transgenic sickle mice. Am J Respir Crit Care Med 2004; 169:687-695.

10. Sabaa N, et al. Endothelin receptor antagonism prevents hypoxia-induced mortality and morbidity in a mouse model of sickle-cell disease. J Clin Invest 2008; 118: 1924-1933.

11. Strouse JJ, et al. Severe pandemic H1N1 and seasonal influenza in children and young adults with sickle cell disease. Blood 2010; 116:3431-3434.

12. Godeau B, et al. Aplastic crisis due to extensive bone marrow necrosis and human parvovirus infection in sickle cell disease. Am J Med 1991; 91:557-558.

13. Styles LA, et al. Phospholipase A2 levels in acute chest syndrome of sickle cell disease. Blood 1996; 87:25732578.

14. Dang NC, Johnson C, Eslami-Farsani M. Haywood LJ. Bone marrow embolism in sickle cell disease: a review. Am J Hematol 2005; 79:61-67.

15. Gibeon D, et al. Lipid-laden bronchoalveolar macrophages in asthma and chronic cough. Respir Med 2014; 108:71-77.

16. Lechapt $\mathrm{E}$, et al. Induced sputum versus bronchoalveolar lavage during acute chest syndrome in sickle cell disease. Am J Respir Crit Care Med 2003; 168:1373-1377.

17. Bope ET, Kellerman RD. Conn's current therapy 2016. Philadelphia, PA: Elsevier Health Sciences, 2015. 
18. Mekontso Dessap A, et al. Pulmonary artery thrombosis during acute chest syndrome in sickle cell disease. Am J Respir Crit Care Med 2011; 184:1022-1029.

19. Brunson A, et al. Increased incidence of VTE in sickle cell disease patients: risk factors, recurrence and impact on mortality. Br J Haematol 2017; 178:319-326.

20. Novelli EM, Huynh C, Gladwin MT, Moore CG, Ragni MV. Pulmonary embolism in sickle cell disease: a casecontrol study. J Thromb Haemost 2012; 10:760-766.

21. Manci EA, et al. Causes of death in sickle cell disease: an autopsy study. Br J Haematol 2003; 123:359-365.

22. Gelfand MJ, Daya SA, Rucknagel DL, Kalinyak KA, Paltiel HJ. Simultaneous occurrence of rib infarction and pulmonary infiltrates in sickle cell disease patients with acute chest syndrome. J Nucl Med 1993; 34:614-618.

23. Kopecky EA, Jacobson S, Joshi P, Koren, G. Systemic exposure to morphine and the risk of acute chest syndrome in sickle cell disease. Clin Pharmacol Ther 2004; 75:140-146.

24. Styles LA, Aarsman AJ, Vichinsky EP, Kuypers FA. Secretory phospholipase $\mathrm{A}(2)$ predicts impending acute chest syndrome in sickle cell disease. Blood 2000; 96: 3276-3278.

25. Ballas SK, et al. Secretory phospholipase A2 levels in patients with sickle cell disease and acute chest syndrome. Hemoglobin 2006; 30:165-170.

26. Styles L, et al. Refining the value of secretory phospholipase A2 as a predictor of acute chest syndrome in sickle cell disease: results of a feasibility study (PROACTIVE). Br J Haematol 2012; 157:627-636.

27. Bargoma EM, et al. Serum C-reactive protein parallels secretory phospholipase A2 in sickle cell disease patients with vasoocclusive crisis or acute chest syndrome. Blood 2005; 105:3384-3385.

28. Nur E, et al. Plasma levels of pentraxin-3, an acute phase protein, are increased during sickle cell painful crisis. Blood Cells Mol Dis 2011; 46:189-194.

29. Elshazly SA, Heiba NM, Abdelmageed WM. Plasma PTX3 levels in sickle cell disease patients, during vaso occlusion and acute chest syndrome (data from Saudi population). Hematology 2014; 19:52-59.

30. Vichinsky EP, et al. Acute chest syndrome in sickle cell disease: clinical presentation and course. Cooperative Study of Sickle Cell Disease. Blood 1997; 89:1787-1792.

31. DeBaun MR, Strunk RC. The intersection between asthma and acute chest syndrome in children with sickle-cell anaemia. Lancet 2016; 387:2545-2553.

32. Chaturvedi S, et al. Rapidly progressive acute chest syndrome in individuals with sickle cell anemia: a distinct acute chest syndrome phenotype. Am J Hematol 2016; 91: 1185-1190.

33. Hassell KL, Eckman JR, Lane PA. Acute multiorgan failure syndrome: a potentially catastrophic complication of severe sickle cell pain episodes. Am J Med 1994; 96: 155-162.

34. Shelat SG. Thrombotic thrombocytopenic purpura and sickle cell crisis. Clin Appl Thromb Hemost 2010; 16: 224-227.

35. Bolanos-Meade J, Keung YK, Lopez-Arvizu C, Florendo $\mathrm{R}$, Cobos E. Thrombotic thrombocytopenic purpura in a patient with sickle cell crisis. Ann Hematol 1999; 78:558559.

36. Castro $\mathrm{O}$, et al. The acute chest syndrome in sickle cell disease: incidence and risk factors. The Cooperative Study of Sickle Cell Disease. Blood 1994; 84:643-649.
37. Creary SE, Krishnamurti L. Prodromal illness before acute chest syndrome in pediatric patients with sickle cell disease. J Pediatr Hematol Oncol 2014; 36:480-483.

38. Buchanan ID, Woodward M, Reed GW. Opioid selection during sickle cell pain crisis and its impact on the development of acute chest syndrome. Pediatr Blood Cancer 2005; 45:716-724.

39. Henderson JN, et al. Reversible posterior leukoencephalopathy syndrome and silent cerebral infarcts are associated with severe acute chest syndrome in children with sickle cell disease. Blood 2003; 101:415-419.

40. Ohene-Frempong K, et al. Cerebrovascular accidents in sickle cell disease: rates and risk factors. Blood 1998; 91: 288-294.

41. Quinn CT, et al. Acute silent cerebral ischemic events in children with sickle cell anemia. JAMA Neurol 2013; 70: 58-65.

42. Adisa OA, et al. Association between plasma free haem and incidence of vaso-occlusive episodes and acute chest syndrome in children with sickle cell disease. Br J Haematol 2013; 162:02-705.

43. Bean CJ, et al. Heme oxygenase-1 gene promoter polymorphism is associated with reduced incidence of acute chest syndrome among children with sickle cell disease. Blood 2012; 120:3822-3828.

44. Ghosh S, et al. Extracellular hemin crisis triggers acute chest syndrome in sickle mice. J Clin Invest 2013; 123: 4809-4820.

45. Paul R, et al. Clinical correlates of acute pulmonary events in children and adolescents with sickle cell disease. Eur J Haematol 2013; 91:62-68.

46. Ambrusko SJ, et al. Elevation of tricuspid regurgitant jet velocity, a marker for pulmonary hypertension in children with sickle cell disease. Pediatr Blood Cancer 2006; 47: 907-913.

47. Chaudry RA, et al. Paediatric sickle cell disease: pulmonary hypertension but normal vascular resistance. Arch Dis Child 2011; 96:131-136.

48. Pashankar FD, Carbonella J, Bazzy-Asaad A, Friedman A. Prevalence and risk factors of elevated pulmonary artery pressures in children with sickle cell disease. Pediatrics 2008; 121:777-782.

49. Quinn CT, et al. Prognostic significance of early vasoocclusive complications in children with sickle cell anemia. Blood 2007; 109:40-45.

50. Araujo JG, et al. Risk factors for acute chest syndrome in patients from low socioeconomic background: a cohort study from Sergipe, Brazil. J Pediatr Hematol Oncol 2011; 33:421-423.

51. Vance LD, et al. Increased risk of severe vaso-occlusive episodes after initial acute chest syndrome in children with sickle cell anemia less than 4 years old: sleep and asthma cohort. Am J Hematol 2015; 90:371-375.

52. Fertrin KY, Costa FF. Genomic polymorphisms in sickle cell disease: implications for clinical diversity and treatment. Expert Rev Hematol 2010; 3:443-458.

53. Galarneau $\mathrm{G}$, et al. Gene-centric association study of acute chest syndrome and painful crisis in sickle cell disease patients. Blood 2013; 122:434-442.

54. Emre U, Miller ST, Rao SP, Rao M. Alveolar-arterial oxygen gradient in acute chest syndrome of sickle cell disease. J Pediatr 1993; 123:272-275.

55. Alhandalous $\mathrm{CH}$, et al. Platelets decline during vasoocclusive crisis as a predictor of acute chest syndrome in sickle cell disease. Am J Hematol 2015; 90:E228-E229. 
56. Vichinsky EP, et al. A comparison of conservative and aggressive transfusion regimens in the perioperative management of sickle cell disease. The Preoperative Transfusion in Sickle Cell Disease Study Group. N Engl J Med 1995; 333:206-213.

57. Cohen RT, DeBaun MR, Blinder MA, Strunk RC, Field JJ. Smoking is associated with an increased risk of acute chest syndrome and pain among adults with sickle cell disease. Blood 2010; 115:3852-3854.

58. Young RC, Jr., Rachal RE, Hackney RL, Jr., Uy CG, Scott RB. Smoking is a factor in causing acute chest syndrome in sickle cell anemia. J Natl Med Assoc 1992; 84:267271.

59. Sadreameli SC, Eakin MN, Robinson KT, Alade RO, Strouse JJ. Secondhand smoke is associated with more frequent hospitalizations in children with sickle cell disease. Am J Hematol 2016; 91:313-317.

60. Glassberg JA, Wang J, Cohen R, Richardson LD, DeBaun MR. Risk factors for increased ED utilization in a multinational cohort of children with sickle cell disease. Acad Emerg Med 2012; 19:664-672.

61. Cohen RT, et al. Environmental tobacco smoke and airway obstruction in children with sickle cell anemia. Chest 2013; 144:1323-1329.

62. Boyd JH, Macklin EA, Strunk RC, DeBaun MR. Asthma is associated with acute chest syndrome and pain in children with sickle cell anemia. Blood 2006; 108:29232927.

63. An $\mathrm{P}$, et al. Elevation of $\operatorname{IgE}$ in children with sickle cell disease is associated with doctor diagnosis of asthma and increased morbidity. J Allergy Clin Immunol 2011; 127: 1440-1446.

64. Strunk RC, et al. Wheezing symptoms and parental asthma are associated with a physician diagnosis of asthma in children with sickle cell anemia. J Pediatr 2014; 164: 821.e1-826.e1.

65. Leong MA, Dampier C, Varlotta L, Allen JL. Airway hyperreactivity in children with sickle cell disease. J Pediatr 1997; 131:278-283.

66. Field JJ, et al. Airway hyperresponsiveness in children with sickle cell anemia. Chest 2011; 139:563-568.

67. Ozbek OY, et al. Airway hyperreactivity detected by methacholine challenge in children with sickle cell disease. Pediatr Pulmonol 2007; 42:1187-1192.

68. Strunk RC, et al. Methacholine challenge in children with sickle cell disease: a case series. Pediatr Pulmonol 2008; 43:924-929.

69. Boyd JH, Moinuddin A, Strunk RC, DeBaun MR. Asthma and acute chest in sickle-cell disease. Pediatr Pulmonol 2004; 38:229-232.

70. Bryant R. Asthma in the pediatric sickle cell patient with acute chest syndrome. J Pediatr Health Care 2005; 19: 157-162.

71. Glassberg J, Spivey JF, Strunk R, Boslaugh S, DeBaun MR. Painful episodes in children with sickle cell disease and asthma are temporally associated with respiratory symptoms. J Pediatr Hematol Oncol 2006; 28:481-485.

72. Knight-Madden JM, Forrester TS, Lewis NA, Greenough A. Asthma in children with sickle cell disease and its association with acute chest syndrome. Thorax 2005; 60: 206-210.

73. Nordness ME, Lynn J, Zacharisen MC, Scott PJ, Kelly KJ. Asthma is a risk factor for acute chest syndrome and cerebral vascular accidents in children with sickle cell disease. Clin Mol Allergy 2005; 3:2.
74. Poulter EY, Truszkowski P, Thompson AA, Liem RI. Acute chest syndrome is associated with history of asthma in hemoglobin SC disease. Pediatr Blood Cancer 2011; 57:289-293.

75. Reagan MM, DeBaun MR, Frei-Jones MJ. Multi-modal intervention for the inpatient management of sickle cell pain significantly decreases the rate of acute chest syndrome. Pediatr Blood Cancer 2011; 56:262-266.

76. Yawn BP, et al. Management of sickle cell disease: summary of the 2014 evidence-based report by expert panel members. JAMA 2014; 312:1033-1048.

77. Haynes J, Jr., Allison RC. Pulmonary edema. Complication in the management of sickle cell pain crisis. Am J Med 1986; 80:833-840.

78. Ahmad FA, Macias CG, Allen JY. The use of incentive spirometry in pediatric patients with sickle cell disease to reduce the incidence of acute chest syndrome. J Pediatr Hematol Oncol 2011; 33:415-420.

79. Bellet PS, Kalinyak KA, Shukla R, Gelfand MJ, Rucknagel DL. Incentive spirometry to prevent acute pulmonary complications in sickle cell diseases. N Engl J Med 1995; 333:699-703.

80. Crabtree EA, et al. Improving care for children with sickle cell disease/acute chest syndrome. Pediatrics 2011; 127: e480-e488.

81. Hsu LL, Batts BK, Rau JL. Positive expiratory pressure device acceptance by hospitalized children with sickle cell disease is comparable to incentive spirometry. Respir Care 2005; 50:624-627.

82. Padman R, Henry M. The use of bilevel positive airway pressure for the treatment of acute chest syndrome of sickle cell disease. Del Med J 2004; 76:199-203.

83. Dean D, et al. Chlamydia pneumoniae and acute chest syndrome in patients with sickle cell disease. J Pediatr Hematol Oncol 2003; 25:46-55.

84. Neumayr L, et al. Mycoplasma disease and acute chest syndrome in sickle cell disease. Pediatrics 2003; 112:87-95.

85. Marti-Carvajal AJ, Conterno LO, Knight-Madden JM. Antibiotics for treating acute chest syndrome in people with sickle cell disease. Cochrane Database Syst Rev 2013; 2:CD006110.

86. Howard J, et al. Prevention of morbidity in sickle cell disease-qualitative outcomes, pain and quality of life in a randomised cross-over pilot trial of overnight supplementary oxygen and auto-adjusting continuous positive airways pressure (POMS2a): study protocol for a randomised controlled trial. Trials 2015; 16:376.

87. Rucknagel DL. The role of rib infarcts in the acute chest syndrome of sickle cell diseases. Pediatr Pathol Mol Med 2001; 20:137-154.

88. Miller ST. How I treat acute chest syndrome in children with sickle cell disease. Blood 2011; 117:5297-5305.

89. Needleman JP, Benjamin LJ, Sykes JA, Aldrich TK. Breathing patterns during vaso-occlusive crisis of sickle cell disease. Chest 2002; 122:43-46.

90. Brookoff D, Polomano R. Treating sickle cell pain like cancer pain. Ann Intern Med 1992; 116:364-368.

91. Jacobson SJ, Kopecky EA, Joshi P, Babul N. Randomised trial of oral morphine for painful episodes of sickle-cell disease in children. Lancet 1997; 350:1358-1361.

92. Uzun B, Kekec Z, Gurkan, E. Efficacy of tramadol vs meperidine in vasoocclusive sickle cell crisis. Am J Emerg Med 2010; 28:445-449.

93. Wright SW, Norris RL, Mitchell TR. Ketorolac for sickle cell vaso-occlusive crisis pain in the emergency depart- 
ment: lack of a narcotic-sparing effect. Ann Emerg Med 1992; 21:925-928.

94. Holbrook CT. Patient-controlled analgesia pain management for children with sickle cell disease. J Assoc Acad Minor Phys 1990; 1:93-96.

95. van Beers EJ, et al. Patient-controlled analgesia versus continuous infusion of morphine during vaso-occlusive crisis in sickle cell disease, a randomized controlled trial. Am J Hematol 2007; 82:955-960.

96. Benjamin LJ, Dampier CD, Jacox AK, Odesina V, Phoenix D, Shapiro B, Strafford M, Treadwell M. Guideline for the management of acute and chronic pain in sickle cell disease. APS Clinical Practice Guidelines Series, No. 1. Glenview, IL: American Pain Society, 1999, pp. 12-13.

97. Emre U, et al. Effect of transfusion in acute chest syndrome of sickle cell disease. J Pediatr 1995; 127:901-904.

98. Gladwin MT, et al. Nitric oxide for inhalation in the acute treatment of sickle cell pain crisis: a randomized controlled trial. JAMA 2011; 305:893-902.

99. Koumbourlis AC, Lee DJ, Lee A. Longitudinal changes in lung function and somatic growth in children with sickle cell disease. Pediatr Pulmonol 2007; 42:483-488.

100. Santoli F, et al. Pulmonary function in sickle cell disease with or without acute chest syndrome. Eur Respir J 1998; 12:1124-1129.

101. Sylvester KP, et al. Impact of acute chest syndrome on lung function of children with sickle cell disease. J Pediatr 2006; 149:17-22.

102. Knight-Madden JM, Hambleton IR. Inhaled bronchodilators for acute chest syndrome in people with sickle cell disease. Cochrane Database Syst Rev 2012; 7:CD003733.

103. Bernini JC, et al. Beneficial effect of intravenous dexamethasone in children with mild to moderately severe acute chest syndrome complicating sickle cell disease. Blood 1998; 92:3082-3089.

104. Kumar R, Qureshi S, Mohanty P, Rao SP, Miller ST. A short course of prednisone in the management of acute chest syndrome of sickle cell disease. J Pediatr Hematol Oncol 2010; 32:e91-e94.

105. Strouse JJ, Takemoto CM, Keefer JR, Kato GJ, Casella JF. Corticosteroids and increased risk of readmission after acute chest syndrome in children with sickle cell disease. Pediatr Blood Cancer 2008; 50:1006-1012.

106. Sobota A, Graham DA, Heeney MM, Neufeld EJ. Corticosteroids for acute chest syndrome in children with sickle cell disease: variation in use and association with length of stay and readmission. Am J Hematol 2010; 85:24-28.

107. Darbari DS, et al. Severe vaso-occlusive episodes associated with use of systemic corticosteroids in patients with sickle cell disease. J Natl Med Assoc 2008; 100: 948-951.

108. Frei-Jones MJ, Field JJ, DeBaun MR. Multi-modal intervention and prospective implementation of standardized sickle cell pain admission orders reduces 30-day readmission rate. Pediatr Blood Cancer 2009; 53:401-405.

109. Strouse JJ, Hulbert ML, DeBaun MR, Jordan LC, Casella JF. Primary hemorrhagic stroke in children with sickle cell disease is associated with recent transfusion and use of corticosteroids. Pediatrics 2006; 118:1916-1924.

110. Atz AM, Wessel DL. Inhaled nitric oxide in sickle cell disease with acute chest syndrome. Anesthesiology 1997; 87:988-990.

111. Chang WL, Corate LM, Sinclair JM, van der Heyde HC. Continuous inhaled nitric oxide therapy in a case of sickle cell disease with multiorgan involvement. J Investig Med 2008; 56:1023-1027.

112. Sullivan KJ, Goodwin SR, Evangelist J, Moore RD, Mehta P. Nitric oxide successfully used to treat acute chest syndrome of sickle cell disease in a young adolescent. Crit Care Med 1999; 27:2563-2568.

113. Gladwin MT, et al. Pulmonary hypertension as a risk factor for death in patients with sickle cell disease. N Engl J Med 2004; 350:886-895.

114. Merrill WW. Incentive spirometry in sickle cell crisis. N Engl J Med 1996; 334:124-125.

115. Howard J, et al. The Transfusion Alternatives Preoperatively in Sickle Cell Disease (TAPS) study: a randomised, controlled, multicentre clinical trial. Lancet 2013; 381:930-938.

116. Anim SO, Strunk RC, DeBaun MR. Asthma morbidity and treatment in children with sickle cell disease. Expert Rev Respir Med 2011; 5:635-645.

117. Cohen RT, et al. Recurrent, severe wheezing is associated with morbidity and mortality in adults with sickle cell disease. Am J Hematol 2011; 86:756-761.

118. Caboot JB, Allen JL. Pulmonary complications of sickle cell disease in children. Curr Opin Pediatr 2008; 20:279287.

119. Boyd JH, Macklin EA, Strunk RC, DeBaun MR. Asthma is associated with increased mortality in individuals with sickle cell anemia. Haematologica 2007; 92:11151118 .

120. Kassim AA, et al. Low forced expiratory volume is associated with earlier death in sickle cell anemia. Blood 2015; 126:1544-1550.

121. Knight-Madden JM, Barton-Gooden A, Weaver SR, Reid M, Greenough A. Mortality, asthma, smoking and acute chest syndrome in young adults with sickle cell disease. Lung 2013; 191:95-100.

122. Charache $\mathrm{S}$, et al. Effect of hydroxyurea on the frequency of painful crises in sickle cell anemia. Investigators of the Multicenter Study of Hydroxyurea in Sickle Cell Anemia. N Engl J Med 1995; 332:1317-1322.

123. Ferster A, et al. Five years of experience with hydroxyurea in children and young adults with sickle cell disease. Blood 2001; 97:3628-3632.

124. Kinney TR, et al. Safety of hydroxyurea in children with sickle cell anemia: results of the HUG-KIDS study, a phase I/II trial. Pediatric Hydroxyurea Group. Blood 1999; 94:1550-1554.

125. Wang WC, et al. A two-year pilot trial of hydroxyurea in very young children with sickle-cell anemia. J Pediatr 2001; 139:790-796.

126. Hankins JS, et al. Long-term hydroxyurea therapy for infants with sickle cell anemia: the HUSOFT extension study. Blood 2005; 106:2269-2275.

127. Almeida CB, et al. Hydroxyurea and a cGMP-amplifying agent have immediate benefits on acute vaso-occlusive events in sickle cell disease mice. Blood 2012; 120:28792888.

128. Almeida CB, et al. Acute hemolytic vascular inflammatory processes are prevented by nitric oxide replacement or a single dose of hydroxyurea. Blood 2015; 126:711720 .

129. Lemonne N, et al. Effects of hydroxyurea on blood rheology in sickle cell anemia: a two-years follow-up study. Clin Hemorheol Microcirc 2017 [Epub ahead of print]; doi:10.3233/CH-170280. 
130. Lebensburger JD, Pestina TI, Ware RE, Boyd KL, Persons DA. Hydroxyurea therapy requires $\mathrm{HbF}$ induction for clinical benefit in a sickle cell mouse model. Haematologica 2010; 95:1599-1603.

131. Ware RE. How I use hydroxyurea to treat young patients with sickle cell anemia. Blood 2010; 115:5300-5311.

132. Hankins J, et al. Chronic transfusion therapy for children with sickle cell disease and recurrent acute chest syndrome. J Pediatr Hematol Oncol 2005; 27:158-161.

133. Miller ST, et al. Impact of chronic transfusion on incidence of pain and acute chest syndrome during the Stroke Prevention Trial (STOP) in sickle-cell anemia. J Pediatr 2001; 139:785-789.

134. Walters MC, et al. Bone marrow transplantation for sickle cell disease. N Engl J Med 1996; 335:369-376.
135. Hsieh MM, Fitzhugh CD, Tisdale JF. Allogeneic hematopoietic stem cell transplantation for sickle cell disease: the time is now. Blood 2011; 118:1197-1207.

Address correspondence to: Shilpa Jain, MD, MPH

Department of Pediatrics Division of Pediatric Hematology-Oncology Women and Children's Hospital of Buffalo Hemophilia Center of Western New York Buffalo, NY 14209

E-mail: sjain@upa.chob.edu

Received for publication August 1, 2017; accepted after revision October 11, 2017. 